\title{
Leveraging the informal private sector in Afghanistan: was key to improving health system
}

\section{Introduction}

Afghanistan faced a significant challenge to creating a functional health system in a post-conflict setting (although Afghanistan may be considered an "intra"-conflict setting). A low-income country recovering from decades of strife, the health care system has been in disarray for many years. Rebuilding the health care system in Afghanistan is currently being undertaken by a number of groups, including the Afghan government, several nongovernmental organizations (NGOs), and the US government. While some progress has been made, many hurdles remain. The health system in Afghanistan has improved dramatically since 2006: With the creation and implementation of the basic package of health services (BPHS) and later the essential package of hospital services (EPHS) through Non-governmental NGOs. ${ }^{1}$ and an accreditation scale pertinent to all health providers with different levels indicating the type of services the provider is certified to deliver. ${ }^{1}$ In this paper, I would like to discuss the reform how accreditation of informal private sector helped improving and will further improve the health system of Afghanistan. I want to go through the health system reform paradigm.

\section{Problem statement}

In Afghanistan, the private sector had an overwhelming hold on the healthcare provision market offering over 1200 (known) service delivery points and many other unknown points. ${ }^{1}$ The USAID funded survey purported that more than half of all service providers were private while other studies showed that this proportion exceeded $90 \%$ in some ruralareas. ${ }^{1}$ The preponderance of the private sector was not seen as a threat to public healthcare, rather an opportunity to expand access and coverage to the hardest to reach populations where the private sector was already established. Though, the comparative advantage of the private sector lies in service delivery and technical efficiency to render such services, quality of this diverse sector was questionable. Most informal providers (unregistered private clinics, drug shops, market vendors, it inerrant vendors, home providers and traditional healers) were excluded from any systems of quality control, accountability or certification. This informal division had virtually no relationship with the formal healthcare sector yet was used by over $60 \%$ of Afghans as their primary point of contact for health care services. A survey of USAID in rural areas came to the conclusion that an appropriate "regulatory environment around private care providers must be established and guidelines need to be put in place to stimulate their appropriate training and monitoring." $", 2$

\section{Proposed reform}

The Afghanistan constitution of 2004 confirms in article 52 that "The state is obliged to provide free means of preventive health care and medical treatment and proper health facilities to all citizens of Afghanistan in accordance with the law." And "The state encourages and protects the establishment and expansion of private medical sector in accordance to the law." ${ }^{3}$ Thus, the proposed reform was the establishment of an accreditation scale pertinent to all health providers with different levels indicating the type of services the provider is
Volume 7 Issue 2 - 2018

\author{
Muhammad Haroon Stanikzai \\ Lecturer at Kandahar Medical Faculty, Kandahar University, \\ Afghanistan
}

Correspondence: Muhammad Haroon Stanikzai, Lecturer at Kandahar Medical Faculty, Kandahar University, Afghanistan, Email mstanik2@jhu.edu

Received: April 17, 2018 | Published: April 30, 2018

certified to deliver. This focused on incorporating traditional and informal providers into the government-recognized health system but applied equally too formal private and public providers. The WHO has identified recruiting private providers into accreditation programs as a principle strategy in order to "increase coverage of products and services with a public health benefit which are affordable for target groups." ${ }^{4}$ The main objectives of the reform were:

a. To create an investor-friendly atmosphere to attract private involvement in clinical establishments.

b. To draft regulations to ensure patient safety and to monitor and control the service delivery of all current and future private clinical establishments in Afghanistan.

c. To ensure that such institutions meet their social responsibility to serve a large percentage of the poor population.

Accreditation was only granted upon compliance with national standards and for a time-limited period (i.e. annual renewal necessary). Workshops and classes were made available at provincial levels so that providers can raise their certification level and continuously work to improve their knowledge and services. Exterior signage and certification documents would indicate to consumers the level a provider has attained. Afghanistan was in prime position to introduce a program featuring an accreditation body accompanied by private provider training and service development. Official government publications and independent research agreed that Afghanistan was at the point where it was able to formalize rapports between public sector and private healthcare providers at district levels and below. ${ }^{1}$ Rapid growth of the private health care sector outpaced public regulation of these providers. With the country-level policies and legislation in place (or in the pipeline), implementation of regulation for the private (particularly informal) sector needed to catch up. Although policy relating to the public-private mix of services was initiated as early as 2003 , to 2006 , there was little communication between informal private providers, policy makers and consumers concurrently. ${ }^{5}$

\section{Implementation}

Rolling out this reform was gradual in order to provide sufficient time for providers to take the necessary steps towards accreditation. Furthermore, providers were not doing so until they were able to 
recognize the value added to their enterprises by this certification. Demand was thus essential in order for the program to be successful. Pertinent infrastructure was established in order to inspire the demand at a community level and provide district level oversight of regulatory processes and training workshops for provider advancement. While initial effects of the program seemed slow coming, eventual gains benefited private providers' profits, supplement public entities and improve quality of services available to consumers. ${ }^{1}$ The primary actors affected by this reform was the government (or other donors) responsible for the necessary inputs to furnish its inception, the private providers, regulatory bodies and consumers. This also impacted public service providers by reducing their patient volume burden.

An example of accrediting female doctors and female birth attendants have demonstrated effectiveness in overcoming social, financial and geographic barriers to family planning access for poor women in the country. The maternal mortality decreased from 1600 to $173 .{ }^{6}$ More than 90 new private clinics were accredited in the country. ${ }^{1}$ Hundreds of workshops were built. Hundreds of health care workers were trained and accredited. ${ }^{1}$ The primary goals were improvement in quality of private healthcare services and expanded access to these services. Ultimately, these two outcomes worked in conjunction to improve the overall health of Afghans. While offering collaborative opportunities, this accreditation program necessitated significant infrastructure investment, namely, the establishment of provincial and district level bureaus to carry out the workshops and monitoring activities. Furthermore, "strategies to improve service access and product uptake -especially by the poor and other priority groups -usually required actions to simultaneously stimulate demand and support provision." Community mobilization and social marketing was important to relay information about the importance of accreditation and the different levels and how to recognize them. These activities also worked to increase consumer demand for accredited providers and thusly, provider demanded for certification.

\section{Advantages and disadvantages}

Private sector already had significant reach that the public sector can piggyback off of to increase access to services. An accreditation scheme ensured the quality of these services by monitoring offered services against mutually agreed quality standards. Another advantage of this program was global evidence offering successful examples of task shifting to informal providers in comparable countries, particularly targeting community case management of febrile and diarrheal illness in children. However, such a program was not simple and required consensus from diverse stakeholders, which proved difficult given that private stakeholders had concerns and feared about integrating with the public sector for fear of being 'swallowed up' by government. Afghanistan system was too immature to support such a reform. Experts state: "high levels of capability are required of accrediting bodies $[\ldots]$ and this strategy may not be feasible in many settings, especially when there are large numbers and different types of single providers and where resources are highly constrained." 5 Working with private providers typically necessitated significant resources and mass mobilization particularly since they were heterogeneous single entities requiring individual outreach. Financial investment for sufficient infrastructure establishment was substantial to assemble the accrediting bodies and monitoring networks as well as consumer-directed demand creation and training centers.

\section{Conclusion}

Leveraging the existing private networks supplemented public sector providers to improve the health of Afghanistan's people. Although the private sector was where the majority of Afghans first seek care, the services provided were often inappropriate or insufficient. These local informal providers were recognized and appreciated by communities; however, "authorities continued to blame and ridicule them. The government worked to translate policy into true development by adopting an immediate implementation plan. The proposed reform was this and addresses both access and quality of healthcare, two elements essential to improving the health of a population. The WHO has determined that, "where there are important target groups who do not have access to priority services, the accreditation of specific services provided by accessible [private sector providers] (both for-profit and NGOs) can be an effective way of increasing coverage and meeting these needs." ${ }^{\prime 8}$

\section{Acknowledgements}

None.

\section{Conflict of interest}

The author has no conflict of interest to declare.

\section{References}

1. Prateeksha Alsi, Hiwotte Amare, Rodrigo Boccanera, et al. Afghanistan private Health sector survey. 2006.

2. Health Public. Patients Acquiring Medical Treatment from India. Ministry of Public Health, Afghan. 2007;20-28.

3. Islamic Republic of Afghanistan Government. Constitution of the Islamic Republic of Afghanistan. 2004;45.

4. Mills A, Brugha R, Hanson K, et al. What can be done about the private health sector in low-income countries? Bull. World Health Organ. 2002;80(4):325-330.

5. www.mohe.com

6. Ministry of Public Health Kabul. Afghanistan Mortality Survey 2010. Mortality. p. 10-15.

7. Smith E, Brugha R, Zwi AB. Working with private sector providers for better healthcare: An introductory guide. 2001.

8. Zwi AB, Brugha R, Smith E. Private healthcare in developing countries: If it is to work, it must start from what users need. BMJ: British Medical Journal. 2001;323(7311):463-464.

9. Ministry of Public Health Kabul. Afghanistan Mortality Survey 2010. Mortality. p. 10-15. 